\title{
The Scientific Study of Happiness and Health Promotion: an Integrative Literature Review ${ }^{1}$
}

\author{
Fabio Scorsolini-Comin ${ }^{2}$ \\ Manoel Antônio dos Santos ${ }^{3}$
}

\begin{abstract}
The article aims to trace the profile of publications concerning the concept of subjective well-being (SWB), considered the scientific study of happiness, as well as discussing the impact of this accumulated understanding on health promotion. The revision was carried out in the databases PubMed, MedLine, PsycINFO, SciELO, LILACS and PEPSIC using the descriptor subjective well-being. Articles published in indexed periodicals between 1970 and 2008 were selected. From the inclusion/exclusion criteria 19 publications were selected in full for discussion. Of these, the majority were related to the health area and did not approach the concept of SWB directly, but touched on this together with the notions of wellbeing, satisfaction and quality of life. There were few publications that approached the term conceptually or that defined the instruments used for the assessment of SWB. Concluding, the results confirm the relevance of the theme for health promotion and the necessity of investigations related to the practices of health professionals.
\end{abstract}

Descriptors: Happiness; Review Literature as Topic; Health Promotion.

\footnotetext{
${ }^{1}$ Supported by Fundação de Amparo à Pesquisa do Estado de São Paulo (FAPESP).

2 Psychologist, Educational Management Specialist, M.Sc. in Psychology. E-mail: scorsolini_usp@yahoo.com.br.

3 Psychologist, Ph.D. in Psychology, Faculty, Faculdade de Filosofia Ciências e Letras, Universidade de São Paulo, SP, Brazil. E-mail: masantos@ffclrp.usp.br.
}

Corresponding Author:

Manoel Antônio dos Santos

Universidade de São Paulo. Faculdade de Filosofia, Ciências e Letras de Ribeirão

Preto. Depatamento de Psicologia e Educação

Av. Bandeirantes, 3900

Bairro Monte Alegre

CEP: 14040-901 Ribeirão Preto, SP, Brasil

E-mail: masantos@ffclrp.usp.br 


\section{O estudo científico da felicidade e a promoção da saúde: revisão integrativa da literatura}

Objetivou-se traçar o perfil das publicações acerca do conceito de bem-estar subjetivo (BES), considerado o estudo científico da felicidade e discutir o impacto do conhecimento acumulado para a promoção da saúde. A revisão foi realizada nas bases PubMed, MEDLINE, PsycINFO, SciELO, LILACS e PEPSIC a partir do descritor subjetive well-being. Foram selecionados artigos publicados em periódicos indexados no período de 1970 a 2008. A partir dos critérios de inclusão/exclusão foram recuperados 19 trabalhos, na íntegra, para discussão. A maioria é relativa à área de saúde e não aborda diretamente o conceito de BES, mas o evoca juntamente com as noções de bem-estar, satisfação e qualidade de vida. Poucos trabalhos abordam a conceitualização do termo ou definem os instrumentos utilizados para a mensuração do BES. Concluindo, os resultados confirmam a atualidade e pertinência do tema para a promoção da saúde e a necessidade de investigações relacionadas à prática dos profissionais de saúde.

Descritores: Felicidade; Literatura de Revisão como Assunto; Promoção da Saúde.

\section{El estudio científico de la felicidad y la promoción de la salud: revisión integradora de la literatura}

El trabajo tuvo como objetivo investigar el perfil de publicaciones referentes al concepto del bienestar subjetivo (BES), así como la discusión del impacto en la promoción de la salud. La revisión fue ejecutada en los bancos de datos PubMed, MedLine, PsyciNFO, SciELO, LILACS y PEPSIC, en el período 1970-2008. A partir de los criterios de inclusión y exclusión fueron recuperados 19 trabajos que fueron analizados completamente. Entre éstos, la mayoría se refería al área de la salud y no abordaba el concepto de BES directamente, sin embargo lo evocaba juntamente con las nociones de bienestar, satisfacción y calidad de vida. Pocos trabajos abordan la conceptualización del término o definen los instrumentos utilizados para la evaluación del BES. Se concluyó que resultados confirman la actualidad y pertinencia del tema para la promoción de la salud y la necesidad de realizar nuevas investigaciones relacionadas con la práctica de los profesionales de la salud.

Descriptores: Felicidad; Literatura de Revisión como Assunto; Promoción de la Salud.

\section{Introduction}

Scientific studies regarding happiness or subjective well-being (SWB) gained momentum with the advent of Positive Psychology, particularly since the 1990s, which proposed a change of focus: From the repair of the negative aspects and of disease to promoting health and positive aspects of the human being. In reviewing the articles related to the theme of happiness or SWB published in this journal in recent years, it was realized that the recent scientific literature has been concerned with related notions such as quality of life $^{(1-2)}$, satisfaction ${ }^{(3)}$ and Health Promotion ${ }^{(4)}$, but there is still a gap in terms of specific studies of SWB and its constituent dimensions.

In the context of scientific knowledge, the term "happiness" has been translated as subjective wellbeing. Thus, the construct of subjective well-being (SWB) has been conceived as the scientific study of happiness and is closely related to health promotion; this is an internal experience of each individual who issues a judgment on how they feel and their degree of satisfaction with life. A previous literature review, using different databases, indicated that, currently, the 
research is directed toward the search for a more precise conceptualization, in addition to the proposal of strategies for broadly and systematically investigating this construct. This evolution is expected in the case of an emerging area of knowledge, in which a multiplicity of theoretical perspectives converge. Thus, a series of conceptual and methodological questions have still not been formulated, which justifies a look that scrutinizes and examines the state of the art. It is important to emphasize that, given the lack of national studies ${ }^{(5)}$, it is difficult to draw comparisons with the international productions, that work predominantly from the cross-cultural perspective, which is closely related to economic indicators, working conditions and socio-cultural characteristics ${ }^{(6-7)}$. This study aims to systematically review the national and international literature on this theme. For this, a literature review was performed, the results of which are presented and discussed in this study.

\section{Happiness and Subjective Well-being (SWB)}

Happiness can be defined as the predominance of the frequency of occurrence of positive emotional experiences over negative ones(8). Quality of life is divided into two dimensions: objective well-being (welfare), which includes the objective circumstances of life (income, education, health, leisure, transport, among other domains) and subjective well-being (well-being), explained by the subjective experiences of life ${ }^{(9)}$. The study of Subjective Well-being (SWB) has as its central objective the understanding of the evaluation that people make of their lives, and may receive other designations, such as happiness, satisfaction, mood state or positive emotions, also being considered, by some authors, a subjective evaluation of quality of life. A contemporary tendency to relate SWB with the promotion of health is noted. The boundaries of these concepts are still confused and, consequently, its activation in terms of how it is measured was often shown to be misleading(5).

Discussing the factors that influence subjective well-being, some authors maintain that it is a construct that is influenced both by cultural aspects (shared experiences that form the basis of a similar way of seeing the world) and heredity ${ }^{(5,9)}$. The sense of the experiences of individuals is constructed socially through beliefs, assumptions and expectations of the world. As culture influences personality and personality influences culture, in a reciprocal relationship, both levels of analysis are fundamental for understanding SWB within a socio-cultural perspective.

\section{Objective}

To review the scientific literature on subjective wellbeing (SWB) attempting to define the profile of work published in indexing sources with the greatest impact in the national and international sphere, to enable better directing of studies relative to this concept.

\section{Methodological Route}

\section{Type of study}

This was an integrative review ${ }^{(10)}$ that summarized past research and drew global conclusions from a particular body of literature. This type of review allows the construction of a broad analysis, contributing to discussions about methods and results of research as well as reflections on the realization of future research. It is therefore necessary to follow standards of accuracy, clarity and criticism in the review of the literature, so that the salient features of the reviewed studies ${ }^{(11)}$ can be identified.

In carrying out this review we used the following steps: selection of the thematic issue, establishment of the criteria for sample selection, analysis and interpretation of results and presentation of the review.

\section{Theoretical framework}

SWB is a construct that has been studied from the perspective of Positive Psychology ${ }^{(12)}$. This theoretical focus is conceived as the scientific study of the strengths and virtues of the individual, investigating the feelings, emotions and positive behavior, which has the final objective of promoting human happiness. It is the scientific and applied focus on the discovery of the qualities of people and on the promotion of their positive functioning(12).

Even having a recently constituted body of knowledge, from the beginning of the 1990s, it has expanded dramatically. The science and practice of Positive Psychology are directed towards identifying and understanding human qualities and virtues, as well as aiding in the sense that people have happier and more productive lives.

\section{Procedure}

To carry out the database search the descriptor (search term) subjective well-being was used. The following indexing databases were consulted: PubMed, MedLine, PsyciNFO, SciELO, LILACS and PEPSIC. 
Inclusion and exclusion criteria were adopted for the recovery of publications. Studies such as theses, dissertations, books and book chapters - except those that directly addressed SWB were excluded. This methodological choice aimed to eliminate publications that have not undergone rigorous evaluation and peer review in order to select only the indexed literature, complemented by publications in full from books with qualified editorial standards. Research reports from areas remote from Psychology were excluded, unless they were strictly related to subjective aspects involved in the health and disease process. Also, studies were excluded from the review that were not directly related to SWB.

In terms of the period covered by the review, as measured by date of publication of the works, studies were selected that had been published between 1970 and 2007. Regarding the language of publication, the search was restricted to studies published in English, Portuguese, Spanish and French.

After the gathering of the publications, the abstracts were read and analyzed according to the established criteria for inclusion/exclusion. The publications selected through this filter were recovered in full and analyzed in depth.

After reading the abstracts and the recovery of the selected publications in full, they were sorted using a protocol designed for this purpose in order to give visibility to the key attributes of each production (subject, language and year of publication, periodical, objectives, theoretical reference, method employed - type of study, participants, instruments used - main results and scope of the conclusions). Thus, articles were assessed individually according to their scientific qualities. After this preliminary approach, an overall reading of the corpus of analysis, created in the previous steps of the integrative review, was performed, seeking to outline the main points and most salient trends in the set of material collected.

The result of this systematic evaluation are presented and discussed in sequence. Importantly, some studies were found in more than one database consulted, the reason why the number of selected studies did not correspond to the number of publications.

\section{Results and discussion}

\section{Literature review}

Employing the adopted inclusion and exclusion criteria, 121 qualified publications were located. The database in which the higher number of publications was found was PubMed. However, the highest percentage of selected publications came from the database PsycINFO, an international database that indexes studies of Psychology and related areas. This result reflects the concern of the publications in focusing on the psychosocial aspects of the construct.

\section{Profile of the publications found}

In relation to language, most of the studies were published in English, with articles in Portuguese and Spanish also appearing in a small proportion. No studies were found in the French language. The bulk of the publications were taken from the area of health - about 120 publications, which represents more than half of all studies found. In this category publications were found that focus on certain diseases, lifestyle habits, studies on the impact on people's health of using specific techniques, medical technology and clinical practice. These studies had a medical focus, work from the perspective of the health/disease process and were mostly found in the PubMed database, which concentrates studies produced in the context of the area of Health, focusing on medical and related areas. However, as the focus of the integrative review was subjective well-being in a broad manner, and not its purely biomedical aspects, the publications of an eminently biological nature were not selected for analysis in this review.

The second thematic approach of greater expression was represented by productions that present reviews of the literature on SWB, totaling 11 publications. These are papers that discuss the concept of SWB, with critical reviews of literature relating SWB with other constructs which possess a certain conceptual proximity, such as psychological well-being and sense of personal control. Other lines of study encountered were those which refer to the development, application or systematic study of measurement instruments, such as scales and questionnaires, which are directly or indirectly connected to SWB (seven articles) and to the quality of working life (eight). Another approach highlighted refers to research into the influence of culture in the studies on happiness and SWB (four publications). Other categories found consisted of publications that study inclusion and/or social adjustment (two publications), psychotherapy (two publications), relationships in general (two publications), psychopathology (one publication) and violence (one publication). Other productions with very specific purposes were also observed and they did not properly constitute a category of analysis. 
In relation to the population studied in specific studies on the concept of subjective well-being, most included research focused on elderly populations. Regarding the year of publication, it was realized that all the productions selected date from 2001 onwards, which shows the relevance of the theme and its recent scientific circulation. In the selection undertaken in this study, scientific publications were concentrated in the year 2005. However, due to the restricted number of publications selected, this aspect needs to be considered relative, although the high productivity observed in the first decade of the new millennium should be noted, as it gives relevance to the theme and confirms its interest for clinical practice in the area of health promotion.

\section{Analysis of included studies}

The first study selected presents a review of publications on subjective well-being published internationally in recent years, establishing a link between them and the epistemological dimension of the concept of well-being(6). The author considers that the current, growing, scientific production about the theme should be analyzed according to a movement that seeks to understand the importance of factors that lead to health, from a positive perspective. For an intervention to be effective in prevention and health promotion, it is important to have an understanding of the complex interactions that determine subjective well-being at the macro-social, micro-social and individual levels ${ }^{(13)}$.

In another study selected, the authors present the results of an investigation that aimed to determine the indices of happiness and SWB, and their relation with academic behavior of university students from different higher education institutions ${ }^{(14)}$. The instruments used were: a biographical data questionnaire and scales about the feeling of happiness, satisfaction, and SWB.

In another publication included in this study, the authors investigated the configuration of the network of adults social relationships and the satisfaction reported with their relationships(15). This study showed that the people with higher satisfaction with their current life are those who receive more emotional support. In another similar study, the author commented on the theories of scientists dedicated to the study of SWB, such as Diener, Lucas and Scollon, and calls into question the scale SWB of the Multidimensional Personality Questionnaire (MPQ) (16). According to the study, among various aspects highlighted, Diener failed to incorporate into his theory the idea of inheritance, supporting the hypothesis that it would affect SWB.
A study with an elderly population investigated how the levels of emotional satisfaction, behavioral reinforcement and status, as well as human social needs related to age, physical loss and subjective well-being, may be correlated(17). According to the research results, emotional satisfaction strongly correlated with age, while status showed low correlation. Emotional satisfaction and behavioral reinforcement showed strong correlation with life satisfaction; status and reinforcement were positively related to positive emotions and negatively related to negative emotions.

Considering the available evidence, another publication states that SWB is a dynamic system for facing the possibility of coping with adversity ${ }^{(18)}$. To the author of this study, SWB would operate in various ways on the experiential level, affecting aspects such as social behavior. In this light, happiness should be investigated within a specific scenario, in a continuous and constant process $^{(18)}$, considering its peculiar dynamism.

Other authors presented a theoretical study describing the influence of beliefs in the way people analyze their lives and regulate their feelings within the concept of SWB(19). The study highlights the relationship between the concept of SWB and other correlates, such as positive thinking, happiness, satisfaction and optimism. Happiness corresponds to the difference between positive and negative emotions, both experienced in the daily life in different situations and intensities. In this concept of SWB, another study relates the model of social cognition to satisfaction with life ${ }^{(20)}$. According to the findings of this research, the variable regarding life satisfaction is related to positive emotions. Another essential dimension of the construct was targeted by an investigation, the results showed that satisfaction with life changes over the years and with the passing of age; the authors argue, however, that this fluctuation depends on the individual variables ${ }^{(21)}$.

In another study selected, the author mentions that the current research in the literature on SWB have minimized the impact of clinical psychology practice for the current reflection on this notion(22). This article criticizes a number of studies that define what SWB is from its causes or from their correlations with other concepts. According to the author, SWB should be considered as a distinct concept, which can assist the individual in their positive adaptation to reality(22).

Other authors seek an approximation with quality of life, a crucial construct in health promotion. For them, quality of life can be defined in terms of life satisfaction, SWB, happiness and morality(23). This 
study investigated the effect of demographics, of health conditions, of affectivity and of age as factors related to the subjective dimension of the concept of quality of life. The correlations obtained revealed the effect of sociodemographic variables and health on the affectivity and age, and indicated that positive emotions contribute to the positive evaluation of quality of life.

Another study examined the interaction between cultural factors and personality variables as predictors of cognitive and emotional aspects, both components of $\mathrm{SWB}^{(24)}$. This investigation confirmed the influence of personality on achievement of life satisfaction, which was corroborated by the results of another study ${ }^{(25)}$.

In another publication selected, the authors addressed SWB in relation to psychological well-being, which refers to changes that occur during the lives of people ${ }^{(26)}$. According to the empirical research carried out in the United States with more than three million participants, these two concepts were closely related and tend to increase with advancing age, with educational level and with extrovert behavior ${ }^{(26)}$. No work was found covering the relationship between these two constructs in the Brazilian context, which would have enabled comparisons between findings in different cultures.

In the field of economics, another study included in this integrative review, examined the social context and its relationship with the assessments of SWB, happiness and health(27). The authors concluded that factors such as: maintaining good levels of family relations, marriage and social engagement, for example, appear as independent dimensions of the level of subjective well-being, but are directly related to happiness and satisfaction, producing an impact on the health of people. In the last selected publication, the authors presented a scale of evaluation of well-being and of quality of life of patients who have had experience of illness, based on self-perception about their relationships ${ }^{(28)}$. This scale, however, was validated within the hospital context and bears a strong relationship with specific aspects, such as illness, mental health and support received during hospitalization, among other aspects.

Considering the techniques and instruments proposed in the included studies, homogeneity was not found, since the few studies that address the instruments used, measure subjective well-being indirectly, with the exception of a national study, which validated an international instrument for investigation of this concept ${ }^{(5)}$. Thus, there are still relatively few studies that address the development and use of instruments such as the Multidimensional Personality Questionnaire
$M P Q^{(16)}$. However, it is important to note here that this instrument, like others mentioned in some publications, does not propose to investigate subjective well-being specifically, but touches on this construct. Thus, there is a lack of valid measures for the study of subjective wellbeing, both at a national level and in an international context, which points to the need for, not only the creation of standardized instruments, but also for the improvement of those that already exist, including cross-cultural adaptation and validation. The very emergence of Positive Psychology, in a still recent move, can contribute to this situation, once SWB becomes one of the central concepts in this approach.

\section{Final considerations}

In general, within the limits of the analysis made, it can be stated that the majority of studies reviewed were situated within the perspective of health promotion. The specific studies on subjective well-being do not significantly stand out in the configuration of the field outlined by this review. The perceived movement, from the analysis of the view offered by the literature, is that current scientific production, much more than discussing the notion of SWB, the problems involved in its formulation, and the theoretical-conceptual premise that supports it, is concerned with how the concept could or should be applied to clinical practice, specifically in health promotion. Attention is focused on defining the extent to which a particular technique or intervention can contribute to the improvement of subjective wellbeing of people, which has a direct implication on the concepts of quality of life and, therefore, on health.

The consequences of different theoretical approaches in knowledge production related to subjective well-being were evident, especially in the variations of conceptions about the object of study and research strategies. Regarding the definition of SWB, the selected studies presented its conceptual contours in a very similar way. This notion, however, is permeated by other concepts that touch on it, such as satisfaction with life, positive emotions, psychological well-being and quality of life, all concepts contemplated by Positive Psychology. Although they are intimately related, these constructs are different and should be considered in their nuances and specificities, which does not occur in most investigations selected. Accordingly, future studies are needed which should discuss a possible semantic dissociation between these concepts when thinking about and investigating well-being. 
As stated in the results presented, various studies included in this integrative review established correlations between the variables of subjective well-being and others, such as cultural context, age and profession. Such studies also have an impact on defining the concept of subjective well-being, as they help to hypothesize which variables would be directly or indirectly related to this construct. Faced with the complexity that the theme evokes, there is an urgent need for more theoretical and methodological refinement, as well as adequate contextualization of the processes of research for better understanding.

From what was explained in the analysis of the profile created from the included studies, there is a need to deepen the knowledge of the factors related to SWB in order to provide greater theoretical density for this field under construction. Conversely, the analysis undertaken is limited by the reduced availability of published studies and by the very limitations of the reading of these that can be made. These studies serve as a route to understanding the scientific production, though do not always possess the necessary range of reflection on theoretical and methodological aspects of SWB.

In relation to the investigations that address subjective well-being from a purely theoretical perspective, or the others, which work only with the practical dimension and the repercussions of this concept in relation to others, such as the quality of life, it has to be highlighted that the possibilities of linking theory and practice should be more emphasized in new research, a move that has been accepted and encouraged by Positive Psychology. Moreover, it would be desirable if these investigations not only conceptually outline the notion, but are concerned with the production of empirical data that would contribute to a consistent delineation of knowledge on subjective well-being in the actions of health promotion. Thus, health professionals could use references to guide their quotidian practice.

This theoretical-practical articulation, ultimately, is necessary to be able to think on the applicability of the construct in planning programs for prevention and intervention, aimed at the transformation of the models and practices, conforming to Positive Psychology, which is concerned with health promotion and healthy and adaptive aspects of development. Certainly this innovative way may prove difficult and complex, because the opening for the new must take place concurrently with the break with established knowledge, so that change will not erase what was built, but will lend a new view of crystallized ways of seeing and understanding the human being. In this sense, the integrative review presented is one more link in a chain, from which it will be possible to elaborate other literature reviews and discuss the impact of these publications on the definition and scientific study of happiness and subjective wellbeing, contributing with conceptual and theoreticalmethodological reflections relevant to the planning of new research in the area, especially of Positive Psychology. Thus, it will be possible to outline new prospects for studies and interventions on the theme.

\section{References}

1. Inouye K, Pedrazzani ES, Pavarini SCI, Toyoda CY. Percepção de qualidade de vida do idoso com demência e seu cuidador familiar: avaliação e correlação. Rev. Latino-Am Enfermagem. 2009; 17(2):187-93.

2. Inouye K, Pedrazzani ES. Nível de instrução, status socioeconômico e avaliação de algumas dimensões da qualidade de vida de octogenários. Rev. Latino-Am Enfermagem. 2007; 15(n.spe):742-7.

3. Schmidt DRC, Dantas RAS. Qualidade de vida no trabalho de profissionais de enfermagem, atuantes em unidades do bloco cirúrgico, sob a ótica da satisfação. Rev. Latino-Am Enfermagem. 2006; 14(1):54-60.

4. Silva JH, Olson J. Promoção da saúde e qualidade de vida entre mães de pré-adolescentes da comunidade de ChuguayanteChile: uma etnografia enfocada. Rev. Latino-Am Enfermagem. 2005; 13(n.spe2):1164-8.

5. Albuquerque AS, Tróccoli BT. Desenvolvimento de uma escala de bem-estar subjetivo. Psicol Teor Pesq. 2004; 20-2:153-64.
6. Wissing JAB. Patterns of psychological well-being and satisfaction with life in cultural context. In: Delle Fave A, editor. Dimensions of well-being: research and intervention. Milano: Franco Angeli; 2006.

7. Jankovic JF, Dittmar $H$. The componential nature of materialistic values and subjective well-being: a comparison of students in Croatia, Germany, and the UK. In: Delle Fave A, editor. Dimensions of well-being: research and intervention. Milano: Franco Angeli; 2006.

8. Pereira CAA. Um panorama histórico-conceitual acerca das subdimensões de qualidade de vida e do bem-estar subjetivo. Arq Bras Psicol. 1997; 49(4):32-48.

9. Lykken D, Tellegen A. Happiness is a stochastic phenomenon. Psychol Sci. 1996; 7:186-9.

10. Beyea SC, Nicoll LH. Writing in integrative review. AORN J. 1998; 67(4):877-80.

11. Ganong LH. Integrative reviews of nursing research. Res Nurs Health. 1987; (10)1:1-11. 
12. Seligman ME. Authentic happiness: Using the new Positive Psychology to realize your potential for lasting fulfilment. London: Nicholas Brealey Publishing; 2002.

13. Díaz Llanes G. El bienestar subjetivo: actualidad y perspectivas. Rev Cubana Med Gen Integr. 2001; 17(6):572-9.

14. Dela Coleta JA, Dela Coleta MF. Felicidade, bem-estar subjetivo e comportamento acadêmico de estudantes universitários. Psicol Estud. 2006; 11(3):533-9.

15. Resende MC, Bones VM, Souza IS. Rede de relações sociais e satisfação com a vida de adultos e idosos. Psicol Am Lat. [internet] 2006 [acesso em: 28 set. 2009]; 5: 0-0. Disponível em: $\quad$ http://pepsic.bvs-psi.org.br/scielo.php?script=sci_ arttext\&pid $=$ S1870-350X2006000100015\&lng =pt\&nrm =iso

16. Lykken DT. Beyond the hedonic treadmill: revising the adaptation theory of well-being. Am Psychol. 2007; 62(6):611-2.

17. Steverink N, Lindenberg S. Which social needs are important for subjective well-being? What happens to them with aging? Psychol Aging. 2006; 21(2):281-90.

18. Shmotkin D. Happiness in the face of adversity: reformulating the dynamic and modular bases of subjective well-being. Rev Gen Psychol. 2005; 9(4):291-325.

19. Caprara GV, Steca P. Affective and social self-regulatory efficacy beliefs as determinants of positive thinking and happiness. Euro Psychol. 2005; 10(4):275-86.

20. Lent RW, Singley D, Sheu HB, Gainor KA, Brenner BR, Treistman D, Ades L. Social cognitive predictors of domain and life satisfaction: exploring the theoretical precursors of subjective well-being. J Couns Psychol. 2005; 52(3):429-42.
21. Mroczek D, Spiro A. Change in life satisfaction during adulthood: findings from the veterans affairs normative aging study. J Pers Soc Psychol. 2005; 88(1):189-202.

22. Lent RW. Toward a unifying theoretical and practical perspective on well-being and psychosocial adjustment. J Couns Psychol. 2004; 51(4):482-509.

23. Efklides A, Kalaitzidou M, Chankin G. Subjective quality of life in old age in Greece: the effect of demographic factors, emotional state and adaptation to aging. Eur Psychol. 2003; 8(3):178-91.

24. Schimmack U, Radhakrishnan P, Oishi S, Dzokoto V, Ahadi S. Culture, personality, and subjective well-being: Integrating process models of life satisfaction. J Pers Soc Psychol. 2002; 82(4):582-93.

25. Suh EM. Culture, identity consistency, and subjective wellbeing. J Pers Soc Psychol. 2002; 83(6):1378-91.

26. Keyes CLM, Shmotkin D, Ryff CD. Optimizing well-being: the empirical encounter of two traditions. J Pers Soc Psychol. 2002; 82(6):1007-22.

27. Helliwell JF, Putnam RD. The social context of well-being. Philos Trans R Soc Lond B Biol Sci. 2004; 359(46):1449-35.

28. Atkinson MJ, Wishart PM, Wasil BI, Robinson JW. The selfperception and relationships tool (S-PRT): a novel approach to the measurement of subjective health-related quality of life. Health Qual Life Outcomes. 2004; 16:2-36.

Received: Mar. 9 2009

Accepted: Mar. $3^{\text {rd }} 2010$ 